\title{
Glucose tablets
}

National Diabetes Information Clearinghouse (NDIC)

\section{Definitions}

Glucose

Defined by National Diabetes Information Clearinghouse (NDIC)

Hypoglycemia

Defined by National Diabetes Information Clearinghouse (NDIC)

\section{Source}

National Diabetes Information Clearinghouse (U.S.). (2009). The diabetes dictionary. [Bethesda, Md.]: U.S. Dept. of Health and Human Services, National Institutes of Health, National Institute of Diabetes and Digestive and Kidney Diseases, National Diabetes Information Clearinghouse.

Chewable tablets made of pure glucose used for treating hypoglycemia. 